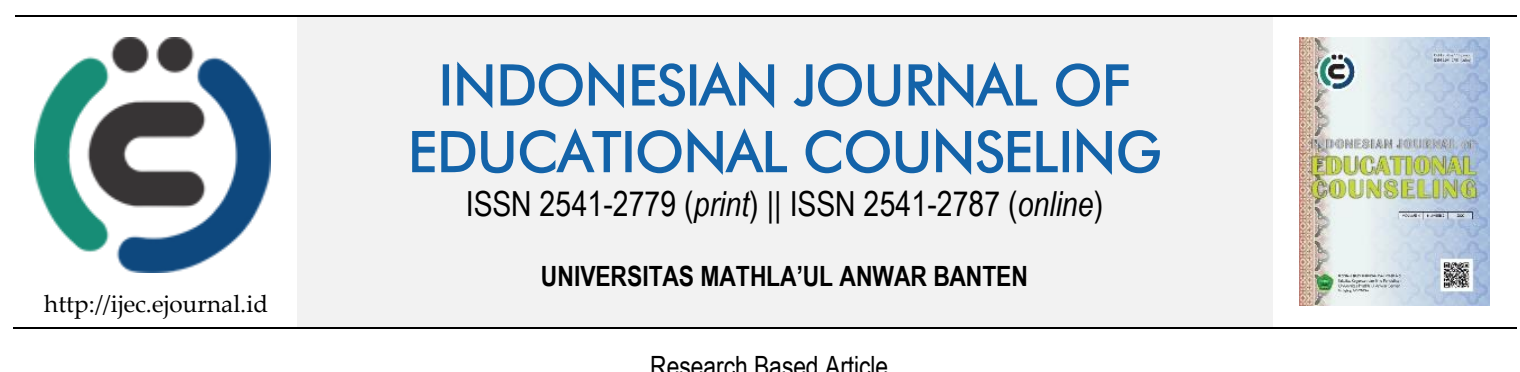

Research Based Article

\title{
Penerapan Humanisme dalam Pembelajaran di Sekolah Dasar
}

\author{
Fitra Nugraha ${ }^{1}$, Wirda Hanim², Eko Siswono ${ }^{2}$ \\ 1, 2 Universitas Negeri Jakarta, Indonesia
}

\begin{tabular}{ll}
\hline Article History & ABSTRACT \\
\hline Received: 05.03.2020 & IMPLEMENTATION OF HUMANISM IN LEARNING OF ELEMENTARY \\
Received in revised form: & SCHOOLS. This study aims to determine how the application of humanism in \\
Accepted: 25.06 .2020 & learning at Cinta Kasih Tzu Chi Elementary School, West Jakarta. This research \\
Available online: 20.07 .2020 & uses a qualitative approach with a case study method in which data collection \\
procedures are in the form of observation, interviews, document analysis or \\
documentation and combination (triangulation). In addition, this study uses \\
data analysis, namely by matching the pattern or pattern matching with the \\
Campbell matchmaking technique. The results of the study found that the \\
application of humanism in learning in grade 1 at Elementary School of Cinta \\
kasih Tzu Chi was using the Cooperative Learning model. The curriculum used \\
is the government's recommended curriculum, namely the 2013 Curriculum \\
with the addition of local content in humanistic culture and character subjects \\
adopted from the teachings of Master Cheng Yen from Taiwan. In the case of \\
learning in the classroom, educators train how to communicate well, remind \\
that they must be empathetic and kind to everyone, for educators' assessment \\
not only from exam results but also daily attitudes. In addition, the role of \\
parents from the research results shows that the role of parents is very \\
important in the success of the humanist application itself. This can be seen \\
from parents who have to monitor attitudes and learning processes when at \\
home.
\end{tabular}

KEYWORDS: Elementary School, Humanism, Learning.

This is an open access article distributed under the terms of the Creative Commons Attribution 4.0 International License, which permits unrestricted use, distribution, and reproduction in any medium, provided the original work is properly cited. ๑) 2020 Fitra Nugraha, Wirda Hanim, Eko Siswono.

\section{PENDAHULUAN}

Pendidikan yang baik tidak terlepas dari pembelajaran yang bisa membuat peserta didik nyaman ketika belajar. Salah satu permasalahan pembelajaran di Jakarta bila dicermati lebih jauh saat ini memang masih cenderung bersifat tekstual. Pembelajaran masih terpaku pada materi yang tertulis di buku, terlepas dari konteks kehidupan yang dialami dalam praktek sehari-hari. Materi dipelajari lebih untuk orientasi ujian, baik ujian

\footnotetext{
${ }^{1}$ Corresponding author's address: Universitas Negeri Jakarta. Jl. Rawamangun Muka, RT.11/RW.14, Rawamangun, Kec. Pulo Gadung, Kota Jakarta Timur, Daerah Khusus Ibukota Jakarta 13220, Indonesia. Email: fitranugraha_9918817041@mahasiswa.unj.ac.id
} 
semester atau ujian akhir dan Impelemtasi dari nilai-nilai yang terkandung dalam materi pelajaran terabaikan.

Jakarta sebagai Kota Metropolitan yang paling berpengaruh di Indonesia mempunyai peran penting dan sebagai acuan perkembangan pendidikan di Indonesia. Sebagai kota yang besar, Jakarta dituntut untuk menyelenggarakan pendidikan yang baik dan berkualitas, walaupun kita mengetahui permasalahan pendidikan di Jakarta sangatlah kompleks, (Ferdi, 2013). Terlebih sekolah dasar yang memiliki peranan penting sebagai peletak dasar pendidikan anak di masyarakat.

Pada umumnya menurut Suharjo sekolah dasar pada dasarnya merupakan lembaga pendidikan yang menyelenggarakan program pendidikan enam tahun bagi anak-anak usia 6-12 tahun, (Rosidah, 2012). Di mana peserta didik sebagai objek belajarnya mendapatkan banyak ilmu dan pengetahuan dalam pembelajaran selama enam tahun lamanya. Disisi lain, pembelajaran di sekolah dasar khususnya di Jakarta harus menyerempakkan peningkatan karakter dengan pengembangan potensi peserta didik agar terciptanya lingkungan yang harmonis. Untuk menanggapi masalah yang dihadapi karakter bangsa saat ini, solusinya adalah reformasi pendidikan untuk membuat pendidikan kurikulum dengan nilai-nilai budaya dan karakter nasional, (Saidek, Raisul, \& Abdoludin, 2016).

Adanya permasalahan di atas membuat proses pembelajaran di sekolah dasar harus terus dievaluasi dan diperbaharui sesuai dengan tuntutan zaman dan karakteristik peserta didik di sekolah. Hal ini dikarenakan, pembelajaran memiliki fungsi menyiapkan peserta didik dengan berbagai keterampilan untuk bekerjasama dengan orang lain (seperti yang harus mereka lakukan di sebagian besar komunitas dan tempat kerja), agar toleran terhadap orang lain, merayakan keragaman individu dan meningkatkan kedalaman pembelajaran dan pengetahuan, (Baines, Blatchford, \& Webster, 2015).

Pembelajaran tidak sekedar mentransfer ilmu pengetahuan kepada peserta didik, tetapi lebih dari itu mentransfer nilai. Selain itu, pembelajaran merupakan kerja budaya yang menuntut peserta didik untuk selalu mengembangkan potensi dan daya kreatifitas yang dimilikinya. Ini dilakukan agar peserta didik bisa hidup mandiri dan berbaur dengan masyarakat. Untuk mencapai tujuan di atas, maka pendidikan humanis adalah salah satu bentuk pendidikan yang harus diterapkan di sebuah lembaga pendidikan, (Idris, 2014). Dalam hal pendidikan di Indonesia, teori pendidikan humanis dianggap sebagai sebuah pendekatan yang akan mampu memecahkan permasalahan pendidikan di Indonesia, (Untari, 2016). Selain itu, kehadiran pendidikan humanis adalah solusi terhadap hilangnya nilai-nilai kemanusiaan dalam proses pendidikan, (Rahma, 2017).

Menurut Aloni (2013), pendidikan humanis memiliki tiga domain dasar kehidupan yaitu 1) individu yang secara harmonis dan autentik menyadari potensi mereka, 2) sebagaimana warga negara yang terlibat dan bertanggung jawab dalam demokrasi, dan 3) sebagai manusia yang memperkaya dan menyempurnakan diri mereka sendiri melalui keterlibatan aktif dengan pencapaian kolektif budaya manusia. Domain tersebutlah yang akan membentuk sikap yang humanis. Sikap humanis ini bukan hanya sekedar mengasah kemampuan berpikir dan keterampilan, tetapi juga melatih etika agar sesama peserta didik maupun pendidik terutama dalam lingkungan sekolah dan keluarga agar saling menghargai dan menghormati, bertanggungjawab dalam segala tindakan, dan aktif dalam keterlibatan pengembangan budaya. 
Dalam penelitian yang dilakukan oleh Idris (2014), pendidikan humanis memandang manusia sebagai manusia, yaitu sebagai makhluk ciptaan Tuhan dengan bakat maupun pembawaan tertentu. Manusia yang manusiawi yang dihasilkan oleh pendidikan yang humanis diharapkan bisa berfikir, merasa, berkemauan, dan bertindak sesuai dengan nilai-nilai luhur kemanusiaan yang bisa mengganti sifat individualistik, egoistik, egosentrik dengan sifat kasih sayang sesama manusia, sifat ingin memberi dan menerima, sifat saling menolong, sifat ingin mencari kesamaan, dan lain sebagainya.

Salah satu sekolah dasar di Jakarta yang telah menggunakan atau menerapkan humanisme dalam pembelajaran di sekolah yaitu Sekolah Dasar Swasta Cinta Kasih Tzu Chi, Jakarta Barat. Sekolah ini telah berkembang menjadi salah satu sekolah terbaik di wilayah Jakarta yang didukung oleh tenaga pengajar professional serta fasilitas yang memadai. Sekolah Dasar Swasta Cinta Kasih Tzu Chi ini mengutamakan pendidikan budi pekerti dan budaya humanis demi mempersiapkan peserta didik menjadi manusia yang berakhlak mulia, berkepribadian santun, produktif, dan mandiri. Selain itu, sekolah ini tidak hanya mengedepankan pencapaian prestasi akademis, tapi juga menanamkan nilainilai budi pekerti dan budaya humanis sebagai kompas dalam pelaksanaan kurikulum.

\section{METODE}

Pendekatan penelitian yang digunakan dalam penelitian ini adalah pendekatan kualitatif. Sedangkan metode penelitian yang digunakan adalah studi kasus. Studi kasus merupakan suatu tipe kajian penelitian kualitatif yang memfokuskan pada suatu objek tunggal, individu, suatu kelompok atau suatu institusi.

Trianto (2010) berpendapat bahwa studi kasus pada dasarnya mempelajari secara intensif seseorang individu atau kelompok yang dipandang mengalami kasus tertentu. Terhadap kasus tersebut peneliti mempelajarinya secara mendalam dan dalam kurun waktu yang cukup lama. Mendalam, artinya mengungkap semua variabel yang dapat menyebabkan terjadinya kasus tersebut dari berbagai aspek. Jadi penelitian studi kasus merupakan penelitian yang menemukan jawaban atas masalah yang dianggap sebagai suatu kasus yang layak untuk diteliti.

Sedangkan Arikunto (2010) mengungkapkan bahwa metode studi kasus sebagai salah satu jenis pendekatan deskriptif, penelitian yang dilakukan secara intensif, terperinci, dan mendalam terhadap suatu organisme (individu), lembaga atau gejala tertentu dengan daerah atau subjek yang sempit.

Pada penelitian ini, peneliti ingin mendeskripsikan atau menggambarkan penerapan humanisme dalam pembelajaran di kelas satu Sekolah Dasar Swasta Cinta kasih Tzu Chi secara luas dan mendalam tanpa melakukan intervensi.

Teknik pengumpulan data menggunakan observasi atau catatan lapangan, wawancara, dan dokumentasi. Dalam mengambil/memilih subjek penelitian, peneliti menggunakan cara purposive dan bersifat snowball sampling.

Dalam penelitian ini juga menggunakan teknik penjodohan Campbell. Analisis data ini menurut Yin (2011), ialah dengan membandingkan pola yang didasarkan pada pola empirik dengan pola yang telah diprediksi di awal sebelum mengumpulkan data. Jika kedua pola ini ada persamaan, hasilnya dapat menguatkan validitas internal studi kasus yang bersangkutan. 


\section{HASIL DAN PEMBAHASAN}

Hasil penelitian didapatkan bahwa penerapan humanisme dalam pembelajaran di kelas satu Sekolah Dasar Swasta Cinta Kasih Tzu Chi diajarkan bagaimana peserta didik itu harus memanusiakan manusia terutama dalam lingkungan sekolah dan keluarga. Dalam artian peserta didik itu menerapkan pembelajaran humanis yang sudah diajarkan di sekolah terutama dalam hal tutur kata, tingkah laku, penampilan, adab kepada teman maupun orang tua, membantu teman, menolong orang yang sedang kesulitan serta selalu membersihkan rumah dan mengerjakan tugas sekolah.

Berikut adalah kegiatan penerapan humanisme di lingkungan Sekolah Dasar Cinta Kasih Tzu Chi.

Pertama melalui kegiatan sekolah, yakni Hari Raya Keagamaan, Peringatan Hari Ibu, Jum' at Bersih, Ibadah, dan Sehat, Pentas Seni, Spelling Bee Competition, Makan Sehat, Karya Wisata, Sport Day, Mandarin Day, Year End Celebration, dan Silent Sitting atau Perenungan.

Kedua melalui pembiasaan rutin di sekolah, seperti:

1) Peserta didik melaksanakan Jum'at ibadah sesuai dengan agama masing-masing.

2) Membiasakan membaca bersama-sama (wajib kunjung perpustakaan)

3) Membiasakan olahraga/senam bersama dalam kegiatan Jum'at sehat.

4) Membiasakan memelihara kebersihan kelas, tanaman, dan lingkungan sekolah bersama-sama.

5) Membiasakan melaksanakan kegiatan belajar tertib efektif bersama.

6) Membiasakan berpakaian seragam sekolah bersih dan rapi setiap hari setiap hari sesuai jadwal.

7) Membiasakan melaksanakan tata tertib sekolah dengan ikhlas.

8) Membiasakan bersaing kompetitif dalam berprestasi.

9) Membiasakan membawa sampah daur ulang setiap hari Selasa dan Jum'at.

10) Membiasakan makan bersama dengan tertib setiap hari Senin dan Selasa.

Ketiga melalui pembiasaan spontan di sekolah, seperti:

1) Membiasakan $3 \mathrm{~S}$ (Senyum, Salam, Sapa) kepada pendidik, karyawan, dan sesama peserta didik.

2) Membiasakan bersikap sopan santun.

3) Membiasakan membuang sampah pada tempat sampah.

4) Membiasakan antri.

5) Membiasakan menghargai pendapat orang lain.

6) Membiasakan minta izin masuk/keluar kelas atau ruangan.

7) Membiasakan menolong atau membantu orang lain.

8) Membiasakan menyalurkan aspirasi melalui media yang ada di sekolah, seperti Majalah Dinding dan Kotak Kritik dan Saran serta aktif dalam Program BK.

9) Membiasakan konsultasi kepada pendidik pembimbing dana tau pendidik lain sesuai kebutuhan

Model pembelajaran yang dilakukan secara umum di Sekolah Dasar Swasta Cinta Kasih Tzu Chi adalah Pembelajaran Kooperatif (Cooperative Learning). Pembelajaran Kooperatif adalah suatu strategi belajar mengajar yang menekankan pada sikap atau 
perilaku bersama dalam bekerja atau membantu di antara sesama dalam struktur kerjasama yang teratur dalam kelompok, yang terdiri dari dua orang atau lebih.

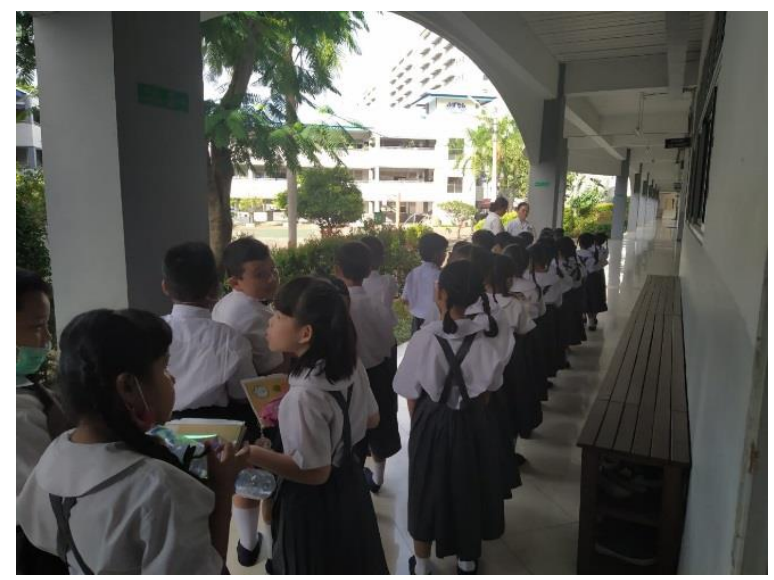

Gambar 1. Peserta didik sedang berbaris sebelum masuk ke kelas

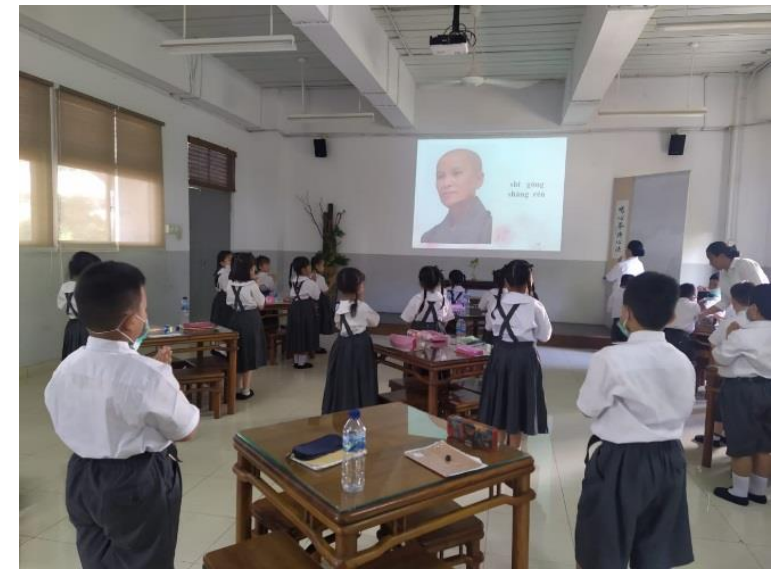

Gambar 2. Peserta didik sedang belajar di dalam kelas budaya humanis

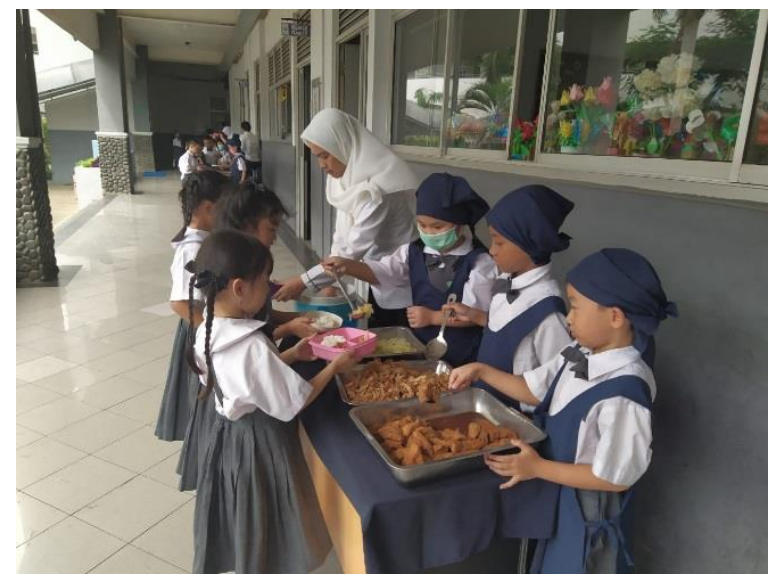

Gambar 3. Peserta didik mengantri untuk mendapatkan makan vegetarian atau makan sehat 


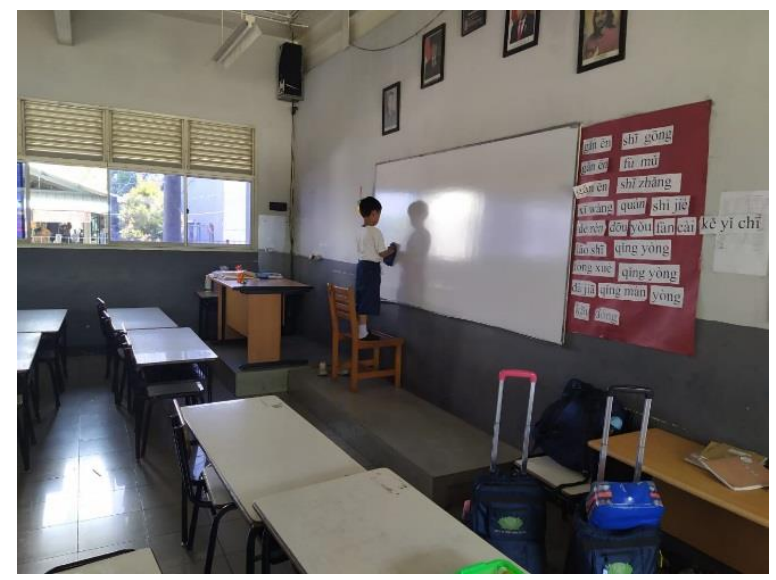

Gambar 4. Peserta didik sedang piket membersihkan kelas setiap pulang sekolah

Malinowski dan Huxley sepakat bahwa humanisme dilandasi pada pemahaman dan empati dengan umat manusia dalam hubungannya dengan lingkungan melalui pengetahuan yang didasarkan pada prosedur ilmiah (penelitian) yang tidak memihak, akan membawa kita ke sikap yang lebih toleran dan berdamai, (Fernandez, 2013).

Dalam istilah pendidikan humanis, kata humanis merupakan kata sifat yang merupakan sebuah pendekatan dalam penelitian. Pendidikan humanis merupakan sebuah teori pendidikan yang dimaksudkan sebagai pendidikan yang menjadikan humanisme sebagai pendekatan. Pendekatan humanistik memandang manusia sebagai orang yang bebas merdeka subjek untuk menentukan arah hidupnya, (Firdaus \& Mariyat, 2017).

Selain itu, menurut Abdurahmansyah pendidikan humanis menjanjikan bahwa proses pembelajaran ditekankan pada aspek utama seperti kebebasan (kebebasan), nilainilai (value), martabat (martabat), dan integritas pribadi (Integritas orang), (Untari, 2016).

Dengan demikian, pendidikan humanis diyakini dapat mengembalikan peran dan fungsi manusia kepada fitrahnya sebagai makhluk yang berpotensi dan manusia yang memiliki sifat manusiawi. Adapun pandangan humanisme tentang pendidikan menurut Ahmad (2017), sebagai berikut:

1) Tujuan pendidikan dan proses pendidikan berasal dari anak (peserta didik). Oleh karenanya, kurikulum dan tujuan pendidikan menyesuaikan dengan kebutuhan, minat, dan prakarsa anak.

2) Peserta didik adalah aktif bukan pasif. Peserta didik memiliki keinginan belajar dan akan melakukan aktivitas belajar apabila mereka tidak difrustasikan belajarnya oleh orang dewasa atau penguasa yang memaksakan keinginannya.

3) Peran pendidik adalah sebagai penasihat, pembimbing, teman belajar bukan penguasa kelas. Tugas pendidik ialah membantu siswa belajar sehingga siswa memiliki kemandirian dalam belajar. Pendidik berperan sebagai pembimbing dan yang melakukan kegiatan mencari dan menemukan pengetahuan bersama peserta didik. Tidak ada pengajaran yang bersifat otoriter, di mana pendidik sebagai penguasa dan peserta didik yang menyesuaikan.

4) Sekolah sebagai bentuk kecil dari masyarakat luas. Pendidikan seharusnya tidak sekadar dibatasi sebagai kegiatan di dalam kelas dengan dibatasi empat dinding 
sehingga terpisah dari masyarakat luas. Karena pendidikan yang bermakna adalah apabila pendidikan itu dapat dimanfaatkan dalam kehidupan masyarakat.

5) Aktivitas belajar harus berfokus pada pemecahan masalah, bukan sekadar mengajarkan mata pelajaran. Pemecahan masalah adalah bagian dari kegiatan kehidupan. Oleh karenanya, pendidikan harus membangun kemajuan peserta didik untuk memecahkan masalah. Kegiatan pendidikan bukan sebagai pemberian informasi atau data dari pendidik kepada peserta didik, yang terbatas sebagai aktivitas mengumpulkan dan mengingat kembali pengetahuan statis.

6) Iklim sekolah harus demokratis dan kooperatif karena kehidupan di masyarakat selalu hidup bersama orang lain, maka setiap orang harus mampu kooperasi dengan orang lain. Namun, dalam realita pendidikan tradisional sering peserta didik dilarang untuk berbicara, berpindah tempat, atau kerjasama dengan peserta didik lain. Iklim demokratis dalam kelas dibutuhkan agar peserta didik dapat hidup secara demokratis di masyarakat.

\section{SIMPULAN}

Sekolah Dasar Swasta Cinta Kasih Tzu Chi merupakan lembaga pendidikan yang berhaluan budaya humanis dalam setiap pembelajarannya. Dalam kaitan pembelajaran sekolah ini menggunakan Kurikulum 2013 yang dipadu dengan penerapan humanisme yang berasal dari Taiwan. Dalam hal pembelajaran di kelas, pendidik melatih cara berkomunikasi yang baik, mengingatkan harus taat dan baik kepada semua orang. Untuk penilaian peserta didik bukan hanya dari hasil ujian tapi juga sikap sehari-hari. Selain itu peran orang tua dari hasil penelitian menunjukkan peran orang tua sangat penting dalam mensukseskan penerapan humanis itu sendiri. Ini terlihat dari orang tua yang harus memantau sikap dan proses pembelajaran ketika di rumah.

Penerapan humanisme dalam pembelajaran di sekolah dasar memiliki banyak pengaruh dalam kehidupan sehari-hari peserta didik. Hal ini disebabkan karena pembelajaran humanisme itu harus di praktekan dalam kehidupan sehari-hari di masyarakat bukan hanya di lingkungan sekolah saja.

\section{REFERENSI}

Ahmad, N. (2017). Pendidikan Islam humanis. Tangsel: Onglam Books.

Aloni, N. (2013). Empowering dialogues in humanistic education. Educational Philosophy and Theory, 45(10), 1067-1081.

Arikunto, S. (2010). Prosedur penelitian: Suatu pendekatan praktek. Jakarta: Rineka Cipta.

Baines, E., Blatchford, P., \& Webster, R. (2015). The challenges of implementing group work in primary school classrooms and including pupils with special educational needs. Education 3-13, 43(1), 15-29.

Creswell, J. W. (2016). Pendekatan metode penelitian kuantitatif, kualitatif dan campuran. Yogyakarta: Pustaka Belajar. 
Fandi, H. A. (2016). Desain pembelajaran yang demokratis dan humanis. Yogyakarta: Ar-Ruzz Media.

Ferdi, W. P. (2013). Pembiayaan pendidikan: Suatu kajian teoritis. Jurnal Pendidikan dan Kebudayaan, 19(4), 565-578.

Fernandez, O. (2013). Malinowski and the new humanism. History of the Human Sciences, 26(2), 70-87. https://doi.org/10.1177/0952695113480974

Firdaus, F. A., \& Mariyat, A. (2017). Humanistic approach in education according to Paulo Freire. At-Ta'dib, 12(2), 26-47.

Hibana., Kuntoro, S. A., \& Sutrisno. (2015). Pengembangan pendidikan humanis religius di madrasah. Jurnal Pembangunan Pendidikan: Fondasi dan Aplikasi, 3(1), 19-30.

Idris, M. (2014). Konsep Pendidikan humanis dalam pengembangan pendidikan Islam. Miqot, 38(2), 417-434.

Rahma, A. (2017). Pendidikan humanis Paolo Freire dalam perspektif pendidikan Islam. Lampung: Institut Agama Islam Negeri Raden Intan Lampung.

Rosidah, W. (2012). Perhatian orang tua pada pendidikan anak di sekolah dasar. Yogyakarta: Universitas Negeri Yogyakarta.

Saidek, A., Raisul, I., \& Abdoludin. (2016). Character issues: Reality character problems and solutions through education in Indonesia. Journal of Education and Practice, 7(17), 158-165.

Sugiyatmi, S. (2012). Kepemimpinan kepala sekolah di SD Gugus Asmorodono Kecamatan Jebres Kota Surakarta. Surakarta: Universitas Muhammadiyah Surakarta.

Trianto. (2010). Pengantar penelitian pendidikan bagi pengembangan profesi pendidikan tenaga kependidikan. Jakarta: Kencana.

Untari, L. (2016). An epistemological review on humanistic education theory. Leksema, $1(1), 59-72$.

Yin, R. K. (2011). Studi kasus: Desain dan metode. Jakarta: Rajawali Pers. 